\title{
$\mathcal{X}^{\text {Reftectoris }}$ What have we learnt from the last ten years of ART?
}

\author{
W D F Venter, FCP (SA), MMed, DTM\&H, DipHIVMan \\ Corresponding author: W D F Venter(fventer@wrhi.ac.za)
}

Professor Francois Venter hails from the Wits Reproductive Health and HIV Institute and Department of Internal Medicine, Faculty of Health Sciences, University of the Witwatersrand, Johannesburg, South Africa

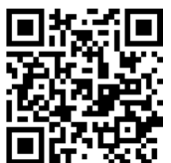

The state programme giving free antiretrovirals (ARVs) started on 1 April 2004 in several large centres across South Africa. For many of us, it seemed unimaginable, after years of running HIV battles with President Thabo Mbeki and his odious Minister of Health, 'Manto' Tshabalala-Msimang, on everything from the cause of HIV to the efficacy of ARVs. A decade later, the state programme is the biggest in the world, with millions of lives saved and families returned back to normal life.

I was involved in the initial design of the programme, and have since been heavily involved in the implementation in rural and urban environments. I like to think about what I've learnt about HIV, and all the things I got wrong. Interestingly, seeing where we are in 2014, much of what has happened in the last decade was as unimaginable as the heady days of starting all those sick, desperate people on ARVs in 2004.

\section{Be ambitious}

I remember Mark Heywood, the human rights crusader for Section 27 , insisting that we put ' $80 \%$ antiretroviral coverage' when we wrote the 2nd National Strategic Plan, released at the end of 2006. The fractious paediatricians also insisted on ambitious prevention of mother-to-child transmission (PMTCT) targets. At the time, there were few places with $>30 \%$ ARV coverage, and reports of poor antenatal PMTCT coverage were everywhere. I thought that they were being silly. By 2010, ARV coverage was close to $80 \%$, and PMTCT transmission rates had fallen below $2 \%$. Even when we designed the programme, in 2002 in dark rooms in the Birchwood Hotel, we continually asked whether drugs were affordable. Before we knew it, we had a pretty good first and second line, which were refined in 2010. Now we sit with a world-class fixed-dose combination and third-line drugs not even available in many developed countries, thanks to the decrease in cost. The Minister's crazy rush of blood to the head, where he wanted to test 20 million South Africans for HIV in one year in 2010, maybe took a few months longer than he had anticipated, but it got there - even though I thought it was impossible - and we're probably now the most tested nation on earth.

\section{We've taught chronic diseases a thing or two about adherence}

I come from the typical physician world of diabetes, hypertension and asthma, where we hug patients who get $>70 \%$ adherence.
The 90\%-plus adherence demanded by ARVs seemed fanciful, until we tried it. Thanks to Médecins Sans Frontières (MSF) and the Treatment Action Campaign (TAC) and their adherence programmes, I've realised that meaningfully involving people in their care and making them understand their disease and how their drugs work, magically transforms them into prize adherence patients. I heard Prof. Steve Reid, a rural advocate, once say that he was amazed at how HIV patients could describe the lifecycle of the virus and evolution of resistance, while diabetic and hypertension patients, when asked what was wrong, would shrug and say: 'I have the high-high'.

\section{We may have saved the world from TB}

If it wasn't for the HIV world seizing the tuberculosis (TB) research and policy agenda, we'd still be stuck with the gross lack of ambition that has left us with third-rate TB drugs and tenth-rate TB diagnostics for decades, couched in one of the most offensive and patronising public health programmes of all - 'DOTS' - while staring down the barrel of a growing multidrug resistance (MDR) nightmare. It staggered me that my patients in Hillbrow could permanently take ARVs $90 \%$ of the time, but the same patients had a $<50 \%$ completion rate of six months of TB therapy at the TB clinic across the road. The story of how they came to the recommended dose of rifampicin (essentially 'what dose can we afford'), and my realisation that, far from what I was taught at med school, MDR was the fault of the programme (bad doses, poor support, poor understanding of the epidemiology), speaks volumes about the kind of history that TB has. It's become better. I still think the programme lacks some creativity and certainly resources, but at least we have a fighting chance, thanks to the increasing focus by clinicians and activists and their demand for integrated therapy and better drugs and diagnostics.

\section{We may have saved the world from old-fashioned public health specialists} Speaking of a lack of ambition, some of the most dispiriting conversations I have had have been with conventional public health specialists, saying that we were diverting resources from their sanitation/food/whatever programmes, with our 'non-sustainable' HIV programmes. Initially, I was defensive, until I realised how they had failed our continent on so many levels for decades whether health promotion or disease prevention. HIV is common, serious, preventable and treatable, yet many did not seem to think 


\section{‘... he was amazed at how HIV patients could describe the lifecycle of the virus and evolution of resistance, while diabetic and hypertension patients, when asked what was wrong, would shrug and say: "I have the high-high".'}

it mattered. ARVs alone have increased life expectancy in South Africa by a decade, in just a few years, making it one of the most powerful public health interventions ever, right up there with good sanitation and vaccines. HIV care has driven energy and creativity into health delivery, and the focus on an evidence base has, at least somewhat, allowed us to question some of the holy cows of public health - from the design of healthcare delivery, the evidence for cancer screening, to obesity definitions and food recommendations - and this has meant a new and critical generation of people who can claim to have public health expertise. Now we routinely demand attention to evidence bases, human rights and patient demands from public health programmes, not always successfully it must be said, but a far cry from the kind of largely irrelevant public health I grew up studying.

\section{Health system inertia may be our biggest challenge}

We sit with a health delivery system largely designed by European colonisers. They've moved on, but we have clung to a clinic-hospital, nurse-doctor model that was out of date 50 years ago. It is especially poor in dealing with an enlightened, google-empowered population asking hard questions of ill-prepared clinical services. Drug-delivery systems and training of health professionals seem constantly to be hamstrung by laws and rules generated by opaque bureaucracies within structures like the Health Professions Council of South Africa (HPCSA) and the Nursing Council - where it is very difficult to see which interest these structures serve. It seems we need massive re-engineering of the health system that goes well beyond what even the idealised National Health Insurance (NHI) looks like.

\section{Attend many meetings and be patient}

One of my epiphanies of the last 15 years of working with the Department of Health (DoH) (it's true also in academia) is s/he who goes to the most meetings, wins. This is frustrating, but attention to process and keeping a beady eye on policy and choices, in an excitable field like HIV where there are many strident and powerful voices, is imperative. You can't rely on minutes and proxies; you've just got to make sure that you get on that Gautrain to Civicus Building with a fully charged iPad and lots of coffee.

\section{We need a strong civil society more than ever}

For a while, we were all big buddies in the Zuma era. Government embraced activists and clinician groups. Post Manto, it was a breath of fresh air to be told how important we were. But we need to be careful - the defensiveness from prominent $\mathrm{DoH}$ members that followed the release of the drug stock-outs reported in December, including death threats and thuggish behaviour by security forces focused on TAC members in the Free State where the stock-outs were the worst, remind us of how prickly and unaccountable politicians and civil servants can be. We still do not have adequate explanation or closure on the bizarre Tara clamp issue, where a harmful device was used in the circumcision programmes in KwaZulu-Natal (KZN). Neliswa 'Peggy' Nkonyeni, ex-health minister for KZN, instrumental in several superb KZN healthcare workers losing their jobs when she was Manto's quack foot soldier, is making a political comeback, and there are many people from Mbekis cabinet who still seem to be successful, despite sitting quietly in his AIDS-denialist circle (c'mon Trevor, what really happened?). At a provincial level, patient advocates and concerned clinicians are routinely treated as optional extras or have their jobs threatened if they rock the boat in local AIDS councils. 'Protection' agencies such as the HPCSA continue to let Wouter Basson earn a handsome living while his victims' families live in poverty, while slapping down non-governmental organisations (NGOs) who support whistle-blowing with spurious appeals to privacy; the HPCSA and Nursing Council seem to think that it's better to let rural people die for want of healthcare, than license foreigners willing to work in places desperate for their skills. Civil society needs your money and your support, for all our future, to take on powerful vested interests.

\section{The private sector, unions, churches and educational institutions have had a largely easy ride}

The excesses of the Mbeki era have allowed for many of these sectors to coast quietly on World AIDS Day platitudes and occasional HIV testing campaigns. I'm struck at Dr Jan Pienaar's aggressive nononsense HIV programme tackling new infections, stigma and fear at Anglo-American's Thermal Coal, and at the empty public statements from banks, shopping chains, universities, unions, major churches (in fairness, I've seen some amazing courage, especially from some Catholic groups), large NGOs, and opposition political parties. We need tangible commitments to testing and treating people, not the candle-lighting hand-wringing we all dread every 1 December.

I visited a very rural hospital in the Eastern Cape in late December simply tarring the disastrous dirt road, now promised for years, would make ambulances accessible, health staff happier and prepared to stay, and allow for better support. The staff accommodation is appalling, and the hospital perennially grapples with understaffing. Not a single South African doctor works there. I was angry at how a middle-income country could let its citizens be neglected in this way. But the senior doctor working there spoke approvingly of the new district manager and how he was trying to get things going, about how she had got cooperation from the nurses by improving their living conditions, how the doctors were happier, and how successful the ARV programme was. We picked up a rural woman looking for a lift en route to the hospital, who spoke loudly and confidently about how she loved 'our hospital' (it was embarrassing that the doctor, who is from Europe, had to translate for me). A week later, back in civilisation, I bumped into a newly appointed senior member of the DoH who I've known and respected for years, who knew all the details of the hospital and the district manager, and rattled off ambitious plans for the next six months, expressing deep dismay at the previous maladministration. There is cause for hope.

We all have a stake in our DoH being as strong as it can be. There is a lot to be angry and concerned about, but it can't stop there. We have to continue to work constructively and critically, even if we are told we are not welcome at times. We need the protective institutions to be challenged, and we need to continue to strengthen civil society, even if it is just giving them much-needed cash. We need to keep re-imagining a better healthcare system. And we need to attend those long meetings.

S Afr J HIV Med 2014;15(1):39-40. DOI:10.7196/SAJHIVMED.1029 